\title{
Temperature effect on microalgae: a crucial factor for outdoor production
}

Monique Ras*(a), Jean-Philippe Steyer*, Olivier Bernard**

(*) INRA, UR050, Laboratoire de Biotechnologie de l'Environnement, avenue des Etangs, Narbonne, F-11100, France

(a) Current address : Station Biologique de Roscoff, CNRS UMR 7139, Place Georges Teissier, BP 74, F-29682 Roscoff cedex, France

(**) Olivier Bernard, BIOCORE, INRIA Sophia Antipolis - Méditerranée, 2004, route des Lucioles, BP 93, 06902 Sophia Antipolis Cedex, France.

\section{Corresponding author}

Olivier Bernard, BIOCORE, INRIA Sophia Antipolis - Méditerranée, 2004, route des Lucioles, BP 93, 06902 Sophia Antipolis Cedex, France. Olivier.bernard@inria.fr

\begin{abstract}
High rate outdoor production units of microalgae can undergo temperature fluctuations. Seasonal temperature variations as well as more rapid daily fluctuations are liable to modify the growth conditions of microalgae and hence affect production efficiency. The effect of elevated temperatures, above optimal growth temperatures, on growth is seldom reported in literature, but often described as more deleterious than low temperatures. Depending on the species, different strategies are deployed to counteract the effect of above optimal temperatures such as energy re-balancing and cell shrinking. Moreover, long term adaptation of certain species over generation cycles has also been proven efficient to increase optimal temperatures. Physical models coupled to biological kinetics are able to predict the evolution of temperature in the growth media and its effect on the growth rate, highlighting the downstream drastic economic and environmental impacts. Regarding the relative elasticity of microalgae towards temperature issues, cell mortality can depend on species or adapted species and in
\end{abstract}


certain cases can be attenuated. These elements can complement existing models and help visualize the effective impacts of temperature on outdoor cultures.

\section{Key words : Microalgae, growth temperatures, acclimation, model predictions}

\section{Introduction}

Unicellular photosynthetic organisms (microalgae and cyanobacteria) are able to convert atmospheric carbon to valuable organic molecules which have growing applications in the energy sector (Benneman 1996; Chisti 2007; Wijffels and Barbosa 2010) as well as high potential in the pharmaceutical and food industries (Milledge 2010). Microalgae can be produced in large scale outdoor facilities (closed photo-bioreactors, or open raceways) in order to improve productivity compared to natural environments (Campbell et al. 2011). However, parameters influencing growth can rapidly change due to such well mixed culture volumes, thus causing less favourable conditions. Besides nutrients and light, microalgae growth efficiency also depends on temperature. Due to the greenhouse effect, microalgae production in outdoor photo-bioreactors experience temperature fluctuations between 10 and $45^{\circ} \mathrm{C}$ in temperate regions (Bechet et al. 2010), thereby including temperatures above tolerated thresholds of most commercialized algae species (Mata et al. 2010). Indeed, most microalgae species are capable of carrying out photosynthesis and cellular division over a wide range of temperatures generally stated between 15 and $30^{\circ} \mathrm{C}$ but with optimal conditions between $20^{\circ} \mathrm{C}$ and $25^{\circ} \mathrm{C}(\mathrm{Li} \mathrm{1980)}$.

Below optimal growth temperatures, an increase in temperature has a positive effect on photosynthesis and cell division. This trend is explained by the enhancement of enzymatic activities related to the Calvin cycle (Falkowski 1980). The relation between growth rate and below-optimal temperatures has been extensively studied and even modeled, most commonly with the Arrhenius equation (Ahlgren 1987). The temperature coefficient Q10 (growth rate increase by a $10^{\circ} \mathrm{C}$ rise in temperature) is often parameterized using the Arrhenius function and is expected to present a value near 2. In other words, for each $10^{\circ} \mathrm{C}$ increase, photosynthesis, cell division and growth should expect to double until unfavorable temperatures are reached. For growth temperatures exceeding the optimal temperature, microalgae growth rate sharply decreases. This is generally explained by heat stress which 
can affect the functionalities of enzymes (inactivation, denaturation) or modify proteins which are involved in photosynthetic processes (Ratkowsky et al. 1983; Salvucci and CraftsBrandner 2004a) thereby inhibiting growth. A bell-shaped growth curve is generally observed for describing temperature response of microalgae growth rate. However, it appears that individual shapes vary widely between species or even clones of the same species (Jorgensen 1968; Falkowski 1977; Suzuki and Takahashi 1995) as well as between different environmental growth conditions.

The need to highlight the impact of temperature on microalgae production rates is evident considering that large scale outdoor production systems, which are liable to undergo extreme temperatures, are today increasingly used to produce economically viable microalgae biomass. This paper will attempt to assess the effects of temperature on microalgae growth, focusing on above optimal temperatures which are liable to occur in well mixed shallow water raceways or narrow photo-bioreactors. The impact of temperature on physiological and biochemical properties of microalgae biomass will be approached in order to describe possible adaptive strategies when facing heat stress conditions. Moreover, authors will introduce the ability of models to predict the occurrence of such conditions and their impact on growth.

\section{Biological and biochemical effects of elevated temperatures}

\section{Optimal growth temperatures and decay}

In general each microalgal species is characterized by an optimal growth temperature (see Table 2). Ideal growth temperatures allow the cell to undergo photosynthesis without modifying any inherent biochemical or physiological parameters. Temperatures providing maximum growth rates are stated between $20^{\circ} \mathrm{C}$ and $25^{\circ} \mathrm{C}$ for mesophilic species, but can increase up to $40^{\circ} \mathrm{C}$ for thermophilic strains (Chaetoceros, Anacystis nidulans) or decrease down to $17^{\circ} \mathrm{C}$ for psychrophilic strains (Asterionella formosa). Figure 1 illustrates the effect of temperature on microalgae growth rates and shows that optimal growth temperatures are liable to be species specific. Chlorella species are well known to have optimal growth rates over a wide range of temperatures. Kessler et al. (1985) who studied growth rates versus optimal temperatures for 17 different Chlorella strains revealed that Chlorella species grew successfully between $26^{\circ}$ (with C. vulgaris, C. prothotecoides) and $36^{\circ} \mathrm{C}$ (with $C$. fusca, C. 
kessleri). Authors highlight accordingly the success of Chlorella species to colonize different types of natural environments and already then suggested this genus as an interesting candidate for high rate outdoor production systems.

It appears in literature that optimal growth temperatures can diverge when studying one same species. Environmental conditions may shift the optimal temperature cursor either way. Indeed, Maddux and Jones (1964) revealed lower optimal temperatures for Tetraselmis sp. when grown in media conditions close to natural waters compared to an enriched nutrient media. The optimal growth temperature of Dunaliella tertiolecta increased by $6^{\circ} \mathrm{C}$ when increasing the sodium chloride content from 0.125 to $1.5 \mathrm{M}$ (Eppley 1972). Optimal temperatures should therefore be associated to the environmental conditions for which they have been obtained.

Optimal growth temperatures for Phaeodactylum tricornutum have been stated at $20^{\circ} \mathrm{C}$ or 23 ${ }^{\circ} \mathrm{C}$ by Fawley et al. (1984) and Kudo et al. (2000) respectively. Such optimal temperature discrepancy might not only be due to the difference in environmental conditions but may result from the process used to estimate this optimal temperature from available data. Generally speaking, the evaluation of optimal temperatures results from an extrapolation process, which is strongly dependent on two temperatures for which the measured growth rate was the highest. Bernard and Rémond (2012) have shown that the uncertainties associated to the estimation of the optimal temperature were generally very large (more than $10^{\circ} \mathrm{C}$ ). This was particularly visible when less than two points were recorded for growth temperatures higher than the optimal temperature.

While increasing temperatures located below optimal enhance growth rates, elevated temperatures on the other hand, beyond optimal, are deleterious. As shown in Figure 1, the general growth vs. temperature curve is asymmetrical, with an asymptotic increase on one hand and a sharp decrease of growth on the other hand. Growth rate decrease is often visualised as linear, with decay values more or less abrupt depending on the species. Lethal temperatures (i.e. zero growth) for mesophilic microalgae have been stated in literature from 30-35 ${ }^{\circ} \mathrm{C}$ onwards (Butterwick et al. 2005; Kudo et al. 2000). The temperature range between optimal and lethal can be more or less broad depending on species. A narrow range might indicate species which are sensitive to heat stress, while a wide range could indicate species which are able to survive by acclimation or adaptation strategies. Several survival strategies have been reported and will be presented subsequently. 


\section{Acclimation and adaptation strategies}

Optimal growth rates generally reflect a good energy balance within the cell. Indeed, growing microalgae attempt to keep a balance between the photosynthetic energy supply (in the thylakoid membranes) and the energy consumption within the Calvin cycle inside the cell. Ideal environmental conditions allow the cell to undergo photosynthesis without modifying any inherent biochemical or physiological functions. On the other hand, an imbalance between energy supply and consumption, generally caused by environmental changes, leads to a modification of the photosynthetic apparatus (unit size, Rubisco activity). Such modification due to temperature conditions is generally called photosynthetic temperature acclimation (Oquist 1983).

Low temperatures generally reduce the carboxylase activity, and if light conditions remain unchanged the energy supply will be overproduced. This imbalance creates light saturation conditions which some cells are familiar with and can hence manage. Chlorella vulgaris, for instance, grew successfully at $5^{\circ} \mathrm{C}$ with a lower chlorophyll content compared to cultures at $27^{\circ} \mathrm{C}$ (Maxwell et al. 1994). Cells which grew at $5^{\circ} \mathrm{C}$ were hence able to adjust their photosynthetic apparatus due to the excitation pressure on the photosystem II caused by the excess of light. Similar acclimation has been found for Dunaliella salina (Krol et al. 1997) and Dunalliella tertiolecta (Levasseur et al. 1990). For Skeletonema costatum, on the other hand, chlorophyll content increased with lowering growth temperature. This was explained by a gained carboxylase activity which ensured the consumption of over-produced energy (Mortain-Bertrand et al. 1988).

On the other hand, the ability for microalgae to grow under high temperatures has been proven to be species-dependent. As stated beforehand, the existence of thermophilic species explains optimal growth temperatures to reach $40^{\circ} \mathrm{C}$ (Chlorella sorokiniana). Nevertheless, whether for mesophilic or thermophilic species, growth beyond optimal temperatures is seldom reported due to the more deleterious effects compared to low temperatures. Indeed, photosynthesis, respiration and growth decline when optimal temperatures are exceeded, thus due to the imbalance between energy demand and ATP production, and to a higher extent due to the inactivation or denaturation of proteins involved in photosynthesis (Raven and Geider, 1988).

By comparing Microcystis aeruginosa and Scenedesmus acutus towards elevated temperature acclimation, Staehr and Birkeland (2006) revealed that both strains exposed higher 
photosynthesis rates and lower respiration rates as well as cell size reduction. Cell shrinking could be a way to counteract the imbalance between catabolic and anabolic processes caused by a temperature increase. Since warming increases the demand for resources, microorganisms are believed to reduce their volume in order to enhance uptake rates and reduce metabolic costs (Atkinson et al. 2003). Similar conclusions were aroused by Garcia et al. (2007), when studying temperature tolerance of Dunaliella species. Authors showed the stronger ability of $D$. salina to withstand supra-optimal temperatures compared to D. viridis, but without knowing if the response was a short-term acclimation or a fixed genotypic adaptation.

Indeed, besides rapid physiological adjustments, slow generational adaptation has also been reported (Iglesias-Prieto et al. 1992). Huertas et al. (2011) showed that Scenedesmus intermedius sampled in continental waters could adapt to $30^{\circ} \mathrm{C}$ after 15 generations, to $35^{\circ} \mathrm{C}$ after 30 generations and to a maximum of $40^{\circ} \mathrm{C}$ after 135 generations. Therefore, by adapting species progressively to elevated temperatures by generational sequences, authors showed that optimal growth temperatures could shift upwards compared to those measured for the ancestral strains. The plasticity of microalgae to genetically adapt to unfavorably warm conditions can offer a long term solution for future outdoor cultures liable to experience elevated temperatures on the long run. Seasonal temperature variations could give enough time for generational adaptation and might insure stable growth rate. Microalgae strains also seem to be predisposed to adaptation depending on previous constraints experienced in its initial environment (Huertas et al. 2011). Prior strain selection from appropriate environments should then be carried out in order to guarantee such an evolutionary potential. On the other hand, rapid temperature fluctuations experienced in shallow water raceways and photobioreactors can reach $10^{\circ} \mathrm{C}$ amplitude over one single day. Therefore, it would be difficult for microalgae to insure generational adaptation over such short time spans.

\section{Biochemical implications}

Photosynthesis

The influence of temperature on photosynthesis is largely caused by the complex kinetics of the ribulose-1,5-bisphosphate (Rubisco). This catalytic enzyme of photosynthesis is involved in two competing physiological pathways, photosynthesis and photorespiration, with a dual carboxylase and oxygenase activity respectively. Salvucci and Crafts-Brandner (2004b) showed that Rubisco enzyme isolated from higher plants increased its carboxylase activity 
under temperatures rising from 5 to $50^{\circ} \mathrm{C}$ and that its activity intensified under saturated $\mathrm{CO}_{2}$ concentrations. These authors also state that above $30^{\circ} \mathrm{C}, \mathrm{CO}_{2}$ affinity for Rubisco is reduced and can hence become a limiting factor for photosynthesis, i.e. reducing biomass production rates. However, when studying the Rubisco activity inside higher plants, a decrease in net photosynthesis above $30^{\circ} \mathrm{C}$ was also observed although saturated $\mathrm{CO}_{2}$ conditions were applied. Results hence suggested that other physiological parameters were affected.

Therefore, the increase of $\mathrm{CO}_{2}$ content in the bubbling gas of microalgae cultures, under high temperatures, might prevent photorespiration and counteract the final effect of temperature on Rubisco. Nevertheless, this is efficient only to a certain extent due to other effects.

In microalgae cells, the most common effects observed for temperatures above $40^{\circ} \mathrm{C}$ for instance, is the inhibition of charge-separation activity of PS II and the inactivation of oxygen evolving capability of PS II (dissociation of $\mathrm{Mn}^{2+}$ ions from the photocatalytic center). The result is the production of oxygen radicals which cause non equilibrium states within the membrane as well as damage to biochemical compounds, such as fatty acid peroxidation, within the cell (Enami et al. 1994; Gombos et al. 1992). In order to counteract the effect of free radicals, several microalgae species grown under elevated temperatures are able to produce anti-radical molecules such as carotenoids. This will be discussed further below.

\section{Chlorophyll content}

As stated earlier, the chlorophyll $a(\mathrm{Chl})$ content of microalgae varies with temperature as an acclimation mechanism to adapt the energy supply of the light phase of photosynthesis to the demand for the dark phase. The resulting effect on the Chl:C ratio (denoted $\theta$ ) has been extensively studied (Geider 1987; Finenko et al. 2003), with 36 microalgae species from 7 taxonomic groups. The combined effect of irradiance and temperature was described by an equation involving 3 coefficients. This ratio $\theta$, (in $\mathrm{g} \mathrm{Chl} a \cdot(\mathrm{g} \mathrm{C})^{-1}$ ) can thus be expressed as a combination of a linear and exponential decrease with respect to temperature (Geider 1987):

$$
\theta^{-1}=a-b T+c E \mathrm{e}^{-k T}
$$

Where $E$ is the irradiance (in mol quanta $\mathrm{m}^{-2} \mathrm{~d}^{-1}$ ) and $\mathrm{T}$ the temperature (in ${ }^{\circ} \mathrm{C}$ ). The coefficients of this equation for three species and 5 taxonomic groups are given in Table 1.

This equation seems to accurately represent the acclimation to temperature at a given light. But it may become inaccurate for temperatures exceeding the optimal growth temperature 
above which growth rate starts to decrease. Data are lacking to characterize the response of $\mathrm{Chl}: \mathrm{C}$ for this temperature domain.

Pigment and lipid production

As stated earlier, microalgae cells which grow in optimal growth conditions present a physiological balance. On the other hand, high temperatures can cause stressful conditions which unbalance the energy equilibrium and enhance the production of excess free radicals. In order to counteract the effect of these harmful compounds and hence ensure growth, cells are able to generate additional molecules with anti-oxidant properties. Pigments such as betacarotene, for instance, have been described to quench over-produced free radicals (Moller et al. 2000) and expose accordingly high value properties against cell damage and cancer. The growing market for carotenoids and interest for bio-produced resources instead of synthesis have driven recent studies on carotene containing algal species. Massive accumulation of beta-carotene inside Dunaliella salina grown under stressful environmental conditions has already been reported in literature (Ben-Amotz et al. 1982; Borowitzka et al. 1984). Increasing the growth temperature of D. salina, from $25^{\circ} \mathrm{C}$ to $35^{\circ} \mathrm{C}$ and under high light exposures, revealed a 5 fold increase of beta-carotene content (Pisal and Lele 2005). By comparing different types of carotenoid contents in 7 D. salina populations, Gomez and Gonzalez (2005) showed that beta-carotene content increased by $20 \%$ when increasing the growth temperature from 15 to $26^{\circ} \mathrm{C}$ while alpha-carotene content decreased by 2 fold. Alphacarotene is known to be more effective than beta-carotene against cell damage (Cramer et al. 2001). The effect of temperature on total lipid content has also been highlighted. Converti et al. (2009) showed that decreasing the temperature from $30^{\circ} \mathrm{C}$ to $25^{\circ} \mathrm{C}$ increased significantly the lipid content of Chlorella vulgaris by 2.5 fold without affecting the growth rate (Figure 2). The same trend was found when Xin et al. (2011) studied the temperature effect on lipid accumulation in Scenedesmus sp: a temperature decrease from $25^{\circ} \mathrm{C}$ to $20^{\circ} \mathrm{C}$ increased the lipid content by 1.7 fold (Figure 2 ) with only a slight effect on the growth rate ( $8 \%$ loss). The growth of these two species hence seem to withstand moderate temperature fluctuations with a general trend showing that temperatures below the maximum growth rate temperatures, would be favourable for lipid accumulation.

Such results prove the fact that temperature conditions, in conjunction with other environmental factors, are able to drive the production of particular types of high value 
constituents in microalgae cells and hence reinforce the need for temperature control over high-rate production systems.

\section{Can we predict temperature fluctuations and its effect on growth?}

The use of high-rate production facilities of microalgae, whether indoor or outdoor facilities, has become a key issue in order to ensure the economic viability of the sector. However, environmental conditions which are not controlled such as temperature can modify growth rates and hence impact the efficiency of a production unit. Growth medium in shallow raceways or narrow tubes, generally used for high rate production, are liable to experience rapid and large temperature fluctuations depending on the geographic locality and on seasonal variations. As reviewed above, temperature conditions have straightforward implications on the growth rate as well as on cell physiology and its biochemical composition. Therefore, temperature is a crucial variable to be taken into account for optimizing the design and the operation of microalgae culturing devices, whether to produce biomass or high value molecules. In this context, it is crucial to develop numerical models which can simultaneously predict the change of temperature in the growth medium and its effect on phytoplankton growth. In this paragraph we review both modelling approaches.

\section{Modelling the evolution of water temperature in cultivation processes}

Various models for predicting temperature fluctuations in lakes, wastewater treatment ponds, aquaculture ponds, and other similar aquatic systems have been described in the literature (Klemetson 1985; Losordo 1991). However, these models could not be universally used since the expression of some heat fluxes were derived from empirical relationships specific to the type of system studied. Other models which are thought to be "universal", i.e. generalizable to any high rate pond based process were recently proposed (Béchet et al. 2010; Béchet et al. 2011) and take into account the location, reactor geometry, light irradiance, air temperature and wind velocity. Such universal models can hence accurately predict the evolving temperature of microalgae growth medium in outdoor facilities. Indeed, these models include the direct and diffuse solar radiation, the radiation from the air and from the ground, the radiation of the water body, the evaporation flux, the heat flux in the $\mathrm{CO}_{2}$ enriched bubbling 
gas, the conductive flux with the ground surface and the convective flux at the surface. They can therefore reproduce the daily dynamics of temperature, including heat and water fluxes. Béchet et al. (2010) suggested a model valid for any culturing device based on an opaque water body of uniform temperature profile. The model was tested against 1 year of experimental data collected from a wastewater treatment high rate algal pond. The model turned out to very accurately predict the measured temperature, with average errors below $1.5^{\circ} \mathrm{C}$.

A mechanistic model was also developed by Béchet et al. (2010) to predict temperature of a column photobioreactors. The model was validated against experimental broth temperature data from an outdoor airlift photobioreactor in Singapore. The model predicted that temperatures may exceed $40{ }^{\circ} \mathrm{C}$ if operated in California, which would mean than none of the currently available commercial algal species would survive. A crucial conclusion of their model is that, for a large scale projection in California, $18000 \mathrm{GJ}$ year ${ }^{-1} \mathrm{ha}^{-1}$ of heat energy must be removed to maintain temperatures below $25^{\circ} \mathrm{C}$, this energy is reduced down to 5500 GJ year ${ }^{-1} \mathrm{ha}^{-1}$ if the temperature is maintained below $35^{\circ} \mathrm{C}$. These energy fluxes deployed to control temperature represent respectively 476 and 145 tons of biodiesel per ha and per year (with a biodiesel PCI of $37.8 \mathrm{MJ} . \mathrm{kg}^{-1}$ ). These figures must be related to the 100 tons of produced lipid per ha and per year which seem to be the maximal productivity achievable by microalgae. When temperature is not regulated, the possible occurrence of mortality under temperature peaks in photobioreactors are probably one of the key problems to be addressed, and whose consequences in terms of costs, energy balance and sustainability at large-scale must be assessed.

\section{Modelling the effect of temperature on growth rate}

In order to quantitatively account for temperature fluctuations in the culture device, it is necessary to use a model predicting the effect of temperature on the microalgal growth rate.

The first phytoplankton dynamic model was proposed by Riley (1947) accounting for phytoplankton growth on the George Banks. Since then, many models describing growth have been developed including the effect of light and nutrient limitation. The first dynamic model for a raceway pond producing microalgae was proposed by Sukenik and Falkowsi (1987). In parallel, other less elaborated models were proposed (Benemann and Tillett 1987; Grobbelaar et al. 1990; Guterman et al. 1990). The underlying models were progressively improved, with 
a better description of photosynthesis (Steele 1962; Vollenweider 1966; Platt et al. 1980; Peeters and Eilers 1978; Geider et al. 1998). However, for these pioneer models, temperature effect was most of the time represented by very simple laws, like the exponential Arrhenius law derived from the Van't Hoff's thermodynamic equation for chemical equilibrium. Such kinetics only describes the increasing phase of the temperature response curve and do not predict the growth drop beyond the optimal temperature. Other functions have also been used (Eppley 1972; Li 1980; Ahlgren 1987), but they all predict an increase of the biological activity (growth rate) with temperature.

However, to quantify the impact of high temperatures reached in outdoor systems on microalgae (Béchet et al. 2011), a model is required over a range of temperatures including those beyond the optimal value. Ratkowsky et al. (1983) were the first to propose a model predicting microbial growth rate over the whole kinetic range, including high temperatures which reduce growth. This model was developed to represent bacterial growth in non-limiting nutrient conditions, then was modified to correct structural problems limiting its identifiability (Lobry et al. 1991; Rosso et al. 1993) and mainly applied for bacterial development in the food industry context (Pinon et al. 2004). This so-called cardinal temperature model with inflexion (CTMI) was used by Bernard and Rémond (2012). The model includes four parameters; three of them are cardinal temperatures with a biological meaning, which makes the model rather straightforward to calibrate:

$\mu_{\max }=\mu_{o p t} \frac{\left(T-T_{\max }\right)\left(T-T_{\min }\right)^{2}}{\left(T_{o p t}-T_{\min }\right)\left[\left(T_{o p t}-T_{\min }\right)\left(T-T_{o p t}\right)-\left(T_{o p t}-T_{\max }\right)\left(T_{o p t}+T_{\min }-2 T\right)\right]}$ for $\quad T_{\min } \leq T \leq T_{\max }$

$T$ is the temperature in degrees Celsius $\left({ }^{\circ} \mathrm{C}\right)$ and $\mu$ is the growth rate in $\mathrm{d}^{-1}$. Parameter $T_{\min }$ is the hypothetical temperature below which the growth rate is assumed to be zero growth, $T_{\max }$ is the temperature above which there is no growth, $T_{\text {opt }}$ is the temperature at which the growth rate is maximal. These three temperature parameters are named cardinal temperatures. The maximal growth rate $\mu_{\text {opt }}$ is reached at $T_{\text {opt }}$. Growth rate is zero except for the temperatures between $T_{\min }$ and $T_{\max }$. 
The model predictions are illustrated in Figure 3 with data of Asterionella formosa. Bernard and Rémond (2012) have shown that the CTMI can accurately represent growth for the 15 species for which data including growth response at high temperatures were available in the literature, as illustrated on Figure 4. They proposed algorithms to identify model parameters and their confidence regions. Based on these algorithms, the growth response of 15 species cultivated in various conditions was identified (Table 2).

Despite its simplicity, it succeeds in assessing the macroscopic influence of temperature resulting from several reaction rates related to photosynthesis and respiration. This model also integrates the light effect by linking the CTMI with a classical model representing the response to light such as Haldane kinetics as suggested by Peeter and Eilers (1978), leading to very good predictions when both light and temperature are considered. This means that, for non photoinhibiting irradiances, the three cardinal temperatures are hardly affected by light intensity. This is illustrated on Figure 5, with data from Sandnes et al. (2005), where the growth rate response obtained for each temperature is normalized with its maximal value. It is noticeable that the temperature response curves superimpose (see Figure 5), showing that the three cardinal temperatures are hardly affected by the light intensity.

The identification algorithm proposed in Bernard and Rémond (2012) can also be used to accurately estimate parameters $\mathrm{T}_{\mathrm{opt}}$ and $\mathrm{T}_{\max }$ from an experimental data set (and of course parameter $\mathrm{T}_{\min }$, but this parameter is more theoretical). Indeed, the estimation of these parameters is not always straightforward and the underlying uncertainty, even if barely assessed in the literature, can be very large. The first part of the CTMI model has the same property as an Arrhenius function (even if the mathematical formulation is different), with a Q10 value near 2. The decreasing part of the temperature response curve turns out to be of shorter width, which makes the curve asymmetric.

The decreasing part of the growth response curve for temperatures higher than $T_{\mathrm{opt}}$ has, so far, received little attention. However, it probably deeply impacts outdoor productivity. Due to its high negative slope, a small temperature variation induces a significant decrease of the growth rate. A temperature regulating system should maintain the system close to the optimal temperature $T_{\mathrm{opt}}$ in order to maximize productivity. Nevertheless it is crucial that the culturing 
device does not reach temperatures higher than $T_{\text {opt }}$ since this could have severe consequences on growth. It is therefore recommended to set up a temperature regulation in the range $\left[\mathrm{T}_{\mathrm{opt}}{ }^{-}\right.$ $\left.\Delta \mathrm{T}, \mathrm{T}_{\mathrm{opt}}\right]$, where $-\Delta \mathrm{T}$ is the temperature regulation accuracy.

The overall effect of temperature on productivity is not straightforward since mass productivity is the product of growth rate and biomass. The effect of temperature on maximum biomass concentration in a culturing system has never been clearly studied. In a photolimited culture, the biomass concentration is determined by the accessibility to light (Cornet 2010). Indeed, respiration rate at the bottom of a raceway should balance the possible growth rate with the remaining light. Since chlorophyll content increases with temperature, higher temperatures may therefore result in a reduced light at the bottom, and finally lower biomass density. As a consequence, the optimal value for the biomass productivity in a culturing system may appear for temperatures lower than the optimal growth rate. These model predictions should however be confirmed with experimental studies.

Such biological models coupled with a model of temperature evolution within the process in response to the variation of heat fluxes can be the basis of optimal temperature control strategies maximizing biomass productivity. They can also be used to forecast the flux of water necessary to compensate evaporation and/or to cool down the process by water spraying.

\section{Conclusion}

The effects of temperatures which exceed thresholds for optimal growth are described as more deleterious than lower temperatures. Indeed, this is visualized by the asymmetrical growth curve vs. temperature. Beyond optimal temperatures, growth rate decrease is linear and reaches lethal temperatures more or less abruptly depending on the species. The occurrence of mortality when temperatures exceed optimal is a reality, but the time over which these changes are experienced is an important factor in order to define the extent of mortality.

This paper has highlighted the ability of certain species to adapt and withstand temperatures which are beyond their defined optimal temperature. Rapid physiological acclimation of cells has also been observed such as cell shrinking. More long term acclimation strategies based on generational sequences during progressive temperature increase have shown that certain species are also able to adapt to above-optimal temperatures. It hence seems that the 
temperature cursor for optimal growth is liable to shift depending on other environmental conditions as well as on the species or pre-adapted populations. However, acclimation strategies are specific and complex mechanisms which cannot be generalized for all species. Computational models show that temperature control in large scale production units would involve an energy cost higher than that energy provided by microalgae (in the case of a biodiesel production unit). Combining models on heat fluxes and on the temperature effect on microalgae may lead to temperature control strategies achieving a tradeoff between productivity and cooling costs.

\section{Acknowledgements:}

This work benefited from the support of the SYMBIOSE research project funded by the French National Research Agency (ANR).

\section{References}

Ahlgren G (1987) Temperature functions in biology and their application to algal growth constants. Oikos 49:177-190

Atkinson D, Ciotti BJ, Montagnes DJS (2003) Protists decrease in size linearly with temperature: ca. 2.5\% degrees C(-1). Proc Biol Sc / The Royal Society 270:2605-11

Baek SH, Shimode S, Han MS, Kikuchi T (2008) Growth of dinoflagellates, Ceratium furca and Ceratium fusus in Sagami Bay, Japan: the role of nutrients. Harmful Algae, 7:729739

Béchet Q, Shilton A, Fringer OB, Muñoz R, Guieysse B (2010) Mechanistic modeling of broth temperature in outdoor photobioreactors. Environ Sc Technol 44(6):2197-2203

Béchet Q, Shilton A, Park JBK, Craggs RJ, Guieysse B (2011) Universal temperature model for shallow algal ponds provides improved accuracy. Environ Sci Technol 45(8):3702-9

Ben-Amotz A, Katz A, Avron M (1982) Accumulation of $\beta$-carotene in halotolerant algae: purification and characterization of $\beta$-carotene-rich globules from Dunaliella bardawil (Chlorophyceae). J Phycol 18:529-537

Benemann JR, Oswald WJ (1996) Systems et economic analysis of microalgae ponds for conversion of CO2 to biomass. US DOE, Pitburgh Energy Technology Centre 
Benemann JR, Tillett DM (1987) Effects of fluctuating environments on the selection of high yielding microalgae. Final report to the Solar Energy Research Institute

Bernard O (1995) Etude expérimentale et théorique de la croissance de Dunaliella tertiolecta (chlorophyceae) soumise à une limitation variable de nitrate : utilisation de la dynamique transitoire pour la conception et la validation des modèles. University Pierre et Marie Curie, Paris VI

Bernard O, Rémond B (2012) Validation of a simple model accounting for light and temperature effect on microalgal growth. Bioresour Technol In press, accepted manuscript

Borowitzka LJ, Borowitzka MA, Moulton T (1984) The mass culture of Dunaliella: from laboratory to pilot plant. Hydrobiologia 116/117:115-121

Butterwick C, Heaney SI, Talling JF (2005) Diversity in the influence of temperature on the growth rates of freshwater algae, and its ecological relevance. Freshw Biol 50(2):291-300

Campbell PK, Beer T, Batten D (2011) Life cycle assessment of biodiesel production from microalgae in ponds. Bioresour Technol 102(1):50-56

Chisti Y (2007) Biodiesel from microalgae. Biotechnol Adv 25(3):294-306

Converti A, Casazza AA, Ortiz EY, Perego P, Del Borghi M (2009) Effect of temperature and nitrogen concentration on the growth and lipid content of Nannochloropsis oculata and Chlorella vulgaris for biodiesel production. Chem Eng Process 48:1146-1151

Cornet JF (2010) Calculation of optimal design and ideal productivities of volumetrically lightened photobioreactors using the constructal approach. Chem Eng Sci 65(2):985-998

Cramer DW, Kuper H, Harlow BL (2001) Carotenoids, antioxidants and ovarian cancer risk in pre- and postmenopausal women. Int J Cancer 94:128-34

Dermoun D, Chaumont D (1992) Modelling of growth of Porphyridium cruentum in connection with two interdependent factors: light and temperature. Bioresour and Technol 42:113-117

Enami I, Kitamura M, Tomo T, Isokawa Y, Ohta H, Katoh S (1994) Is the primary cause of thermal inactivation of oxygen evolution in spinach PS II membranes release of the extrinsic $33 \mathrm{kDa}$ protein or of Mn? Biochi. Biophys Acta 1186:52-58

Eppley RW (1972). Temperature and phytoplankton growth in the sea. Fish Bull 70:10631085

Eppley RW, Sloan PR (1966). Growth rates of marine phytoplankton: correlation with light absorption by cell chlorophyll a. Physiol Plantarum 19(1): 47-59

Falkowski PG (1977) The adenylate energy charge in marine phytoplankton: the effect of temperature on the physiological state of Skeletonema costatum. Biol Ecol 27:37-45

Falkowski PG (1980) Light-shade adaptation in marine phytoplankton. In PG Falkowski [ed.], Primary productivity in the sea p99-119 Plenum 
Fawley MW (1984) Effects of light intensity and temperature interactions on growth characteristics of Phaeodactylum tricornutum (Bacillariophyceae). J Phycol 20:67-72

Finenko ZZ, Hoepffner N, Williams, Piontkovski, SA (2003) Phytoplankton carbon to chlorophyll a ratio: response to light, temperature and nutrient limitation. Mar Ecol Journ II(2):40-64

García F, Freile-Pelegrín Y, Robledo D (2007) Physiological characterization of Dunaliella $s p$. (Chlorophyta, Volvocales) from Yucatan, Mexico. Bioresour Technol 98(7):1359-65

Geider RJ (1987). Light and temperature dependence of the carbon to chlorophyll a ratio in microalgae and cyanobacteria: implications for physiology and growth of phytoplankton. New Phytol 106(1):1-34

Geider RJ, MacIntyre HL, Kana TM (1998) A dynamic regulatory model of phytoplanktonic acclimation to light, nutrients, and temperature. Limnol Oceanogr 43:679-694

Gombos Z, Wada H, Murata N (1992) Unsaturation of fatty acids in membrane lipids enhances tolerance of the cyanobacterium Synechocystis PCC6803 to low-temperature photoinhibition. P Natl Acad Sci USA 89(20):9959-63

Gomez PI, Gonzalez MA (2005) The effect of temperature and irradiance on the growth conditions. Biol Res 38:151-162

Grobbelaar JU, Soeder CJ, Stengel E (1990) Modeling algal productivity in large outdoor cultures and waste treatment systems. Biomass 21:297-314

Guterman H, Vonshak A, Ben-Yaakov S (1990) A macromodel for outdoor algal mass production. Biotechnol Bioeng 35(8):809-819

Huertas IE, Rouco M, López-Rodas V, Costas E (2011) Warming will affect phytoplankton differently: evidence through a mechanistic approach. Proc Biol Sc / The Royal Society (April)

Iglesias-Prieto R, Matta JL, Robins WA, Trench, RK (1992) Photosynthetic response to elevated temperature in the symbiotic dinoflagellate Symbiodinium microadriaticum in culture. P Natl Acad Sci USA 89(21):10302-5

Jørgensen EG (1968) The adaptation of plankton algae. II. Aspects of the temperature adaptation of Skeletonema costatum. Physiol P1 21:423-427

Kessler E (1985). Upper limits of temperature for growth in Chlorella. Plant Syst Evol $151: 67-71$

Klemetson S, Rogers G (1985) Aquaculture pond temperature modelling. Aquacult Eng 4(3):191-208.

Krol M, Maxwell DP, Huner NPA (1997) Exposure of Dunaliella salina to low temperature mimics the high light- induced accumulation of carotenoids and the carotenoid binding protein (Cbr). Plant Cell 38(2):213-216 
Kudo I, Miyamoto M, Noiri Y, MaitaY (2000) Combined effects of temperature and iron on the growth and physiology of the marine diatom Phaeodactylum tricornutum (Bacillariophyceae), J Phycol 36:1096-1102

Levasseur ME, Morissette JC, Popovic R, Harrison P (1990). Effects of long term exposure to low temperature on the photosynthetic apparatus of Dunaliella tertiolecta (Chlorophyceae). J Phycol 26:479-484

Li WKW (1980) Temperature adaptation in phytoplankton: Cellular and photosynthetic characteristics. In: Falkowski PG (ed) Primary productivity in the sea. Plenum Press New York 259-279

Lobry JR, Rosso L, Flandrois JP (1991) A FORTRAN subroutine for the determination of parameter confidence limits in non-linear models. Binary 3:86-93

Losordo TM, Piedrahita RH (1991) Modelling temperature variation and thermal stratification in shallow aquaculture ponds. Ecol Model 54(3-4):189-226.

Maddux WJ, Jones RF (1964) Some interactions of temperature, light intensity, and nutrient concentration during the continuous culture of Nitzschia closterium and Tetraselmis sp. Limnol Oceanogr 9:79-86

Mata TM, Martins AA, Caetano NS (2010) Microalgae for biodiesel production and other applications: A review. Renew Sust Energ Rev 14(1):217-232

Maxwell DP, Fal S, Trick CG, Huner N (1994) Growth at low temperature mimics high-light acclimation in Chlorella vulgaris. Plant physiol 105(2):535-543

Milledge JJ (2010). Commercial application of microalgae other than as biofuels: a brief review. Rev Environ Sc and Bio/Technol 10(1):31-41

Mitrovic SM, Hitchcock JN, Davie AW, Ryan DA (2010) Growth responses of Cyclotella meneghiniana (Bacillariophyceae) to various temperatures. J Plankton Res 32(8):12171221

Møller AP, Biard C, Blount JD, Houston DC, Ninni P, Saino N, Surai PF (2000) Carotenoiddependent signals: indicators of foraging efficiency, immunocompetence, or detoxification ability? Avian Poult Biol Rev 11:137-159

Mortain-Bertrand A, Descolas-Gros C, Jupin H (1988) Pathway of dark inorganic carbon fixation in two species of diatoms: influence of light regime and regulator factors on diel variations. J Plankton Res 10:199-217

Öquist G 1983. Effects of low temperature on photosynthesis. Plant Cell Environ 6:281-300

Peeters JCH, Eilers P (1978) The relationship between light intensity and photosynthesis: a simple mathematical model. Hydrobiol Bull 12:134-136

Pinon A, Zwietering M, Perrier L, Membre JM, Leporq B, Mettler E, Thuault D (2004) Development and validation of experimental protocols for use of cardinal models for prediction of microorganism growth in food products. Appl Environ Microb 70:10811087 
Pisal DS, Lele SS (2005) Carotenoid production from microalgae, Dunaliella salina. Indian J of Biotechnol 4:476-483

Platt T, Gallegos CL, Harrison WGH (1980) Photoinhibition of photosynthesis in natural assemblages of marine phytoplankton. J Mar Res 38:687-701

Ratkowsky DA, Lowry RK, McMeekin TA, Stokes AN, Chandler RE (1983) Model for bacterial culture growth rate throughout the entire biokinetic temperature range. J Bacteriol 154:1222-1226

Raven JA, Geider RJ (1988) Temperature and algal growth. New Phytol 110:441-461

Riley GA (1947) Factors controlling phytoplankton populations on Georges Bank. J Mar Res 6:54-73

Rosso L, Lobry JR, Flandrois JP (1993) An unexpected correlation between cardinal temperatures of microbial growth highlighted by a new model. J Theor Biol 162:447-463

Salvucci ME, Crafts-Brandner SJ (2004a) Inhibition of photosynthesis by heat stress: the activation state of Rubisco as a limiting factor in photosynthesis. Physiol Plant 120(2):179-186

Salvucci ME, Crafts-Brandner SJ (2004b) Relationship between the heat tolerance of photosynthesis and the thermal stability of Rubisco activase in Plants from contrasting thermal environments 1 . Society 134:1460-1470

Sandnes JM, Källqvist T, Wenner D, Gislerød HR (2005) Combined influence of light and temperature on growth rates of Nannochloropsis oceanica: linking cellular responses to large-scale biomass production. J App Phycol 17(6):515-525

Sorokin C, Krauss RW (1962). Effects of Temperature and Illuminance on Chlorella Growth uncoupled from cell division. Plant Physiol 37, 37-42

Staehr P, Birkeland MJ (2006) Temperature acclimation of growth, photosynthesis and respiration in two mesophilic phytoplankton species. Phycol 45(6):648-656

Steele JH (1962) Environmental control of photosynthesis in the sea. Limnol Oceanogr 7:137150

Sukenik A, Falkowski PG (1987) Potential enhancement of photosynthetic energy conversion in algal mass culture. Biotech Bioeng 30:970-977

Suzuki Y, Takahashi M (1995) Growth responses of several diatom species isolated from various environments to temperature. J Phycol 31:880-888

Ukeles R (1961) The effect of temperature on the growth and survival of several marine algal species. The Biol Bull 120(2):255

Vollenweider RA (1966) Calculation models of photosynthesis-depth curves and some implications regarding day rate estimates in primary production measurements. In G. C. R. (Ed.) (pp. 426-457) Uni. Calif 
Wijffels RH, Barbosa MJ (2010) An outlook on microalgal biofuels. Science (New York NY) 329(5993):796-9

Xin L, Hong-ying H, Yu-ping Z (2011) Growth and lipid accumulation properties of a freshwater microalga Scenedesmus $s$. under different cultivation temperature. Bioresour Technol 102:3098-3102 


\begin{tabular}{lccccc}
$\begin{array}{l}\text { Species } \\
\text { and taxonomic groups }\end{array}$ & $\begin{array}{c}\text { Temperature } \\
\text { Range }\left({ }^{\circ} \mathbf{C}\right)\end{array}$ & $\mathbf{a}$ & $\mathbf{b}$ & $\mathbf{c}$ & $\mathbf{k}$ \\
\hline Skeletonema costatum & $0-22$ & $34.5(4.1)$ & $0.60(0.20)$ & 28.5 & $0.147(0.04)$ \\
Leptocylindricus danicus & $5-20$ & $36.8(2.0)$ & $0.45(0.18)$ & 56.2 & $0.140(0.02)$ \\
Phaeodactylum tricornutum & $20-25$ & $64.0(4.6)$ & $2.03(1.10)$ & 39.2 & $0.139(0.05)$ \\
Bacillariophyceae* & $5-25$ & $42.0(3.7)$ & $1.07(0.19)$ & 55.1 & $0.165(0.03)$ \\
Dinophyceae & $15-25$ & $74.7(2.3)$ & $0.96(0.23)$ & 50.0 & $0.150(0.02)$ \\
Prymnesiophyceae & $16-25$ & $53.5(3.1)$ & $0.92(0.47)$ & 60.8 & $0.150(0.09)$ \\
Cyanophyceae & $15-36$ & $57.0(6.2)$ & $0.80(0.36)$ & 142.6 & $0.184(0.03)$ \\
Chlorophyceae & $20-36$ & $17.6(7.2)$ & $0.18(0.58)$ & 35.0 & $0.148(0.02)$
\end{tabular}

Table 1. Coefficients describing $\theta=\mathrm{Chl}: \mathrm{C}$ with temperature and irradiance for various species and taxonomic groups (standard deviation in brackets). Extracted from Finenko et al. (2003). 


\begin{tabular}{llcccc}
\multicolumn{1}{c}{ specie } & reference & $\mathbf{T}_{\min }$ & $\mathbf{T}_{\text {opt }}$ & $\mathbf{T}_{\max }$ & $\boldsymbol{\mu}_{\text {opt }}$ \\
\hline Asterionella formosa & Butterwick et al. (2005) & -7.3 & 20.1 & 29.8 & 1.6 \\
Ceratium furca & Baek et al. (2008) & 8.4 & 24.4 & 32.1 & 0.6 \\
Ceratium furcoides & Butterwick et al. (2005) & 6.9 & 22.3 & 30 & 0.3 \\
Ceratium fusus & Baek et al. (2008) & 4.2 & 26.5 & 30.7 & 0.5 \\
Chlorella pyrenoidosa & Sorokin and Krauss (1962) & 5.2 & 38.7 & 45.8 & $2.0^{*}$ \\
Cryptomonas marssonii & Butterwick et al. (2005) & -2.4 & 15.9 & 30.3 & 0.8 \\
Cyclotella meneghiniana (Lake Kinneret) & Mitrovic et al. (2010) & -14.8 & 26.4 & 28.3 & $1.3^{*}$ \\
Dinobryon divergens & Butterwick et al. (2005) & -5.8 & 17 & 28.4 & 0.7 \\
Dunaliella tertiolecta & Eppley (1972); Ukeles (1961); Eppley & 5.0 & 32.6 & 38.9 & $3.9^{*}$ \\
& and Sloan (1966); Bernard (1995) & & & & \\
Nannochloropsis oceanica & Sandnes et al. (2005) & -0.2 & 26.7 & 33.3 & $1.8^{*}$ \\
Phaeodactylum tricornutum & Kudo et al. (2000); Fawley et al. & -27.7 & 22.5 & 25.2 & $1.8^{*}$ \\
& (1984) & & & & \\
Porphyridium cruentum & Dermoun et al. (1992) & 5.8 & 19.1 & 30 & 1.3 \\
Scenedesmus sp. & Xin et al. (2011) & -3.1 & 26.3 & 32.7 & 0.8 \\
Skeletonema costatum & Butterwick et al. (2005) & 8 & 24.5 & 33 & 1 \\
Tychonema bourrelyi & Butterwick et al. (2005) & 0.4 & 21.8 & 30 & 1
\end{tabular}

Table 2. Cardinal temperatures and optimal growth rates for 15 species. (*: condition providing highest growth rate for this species). Bernard and Rémond, 2012. 


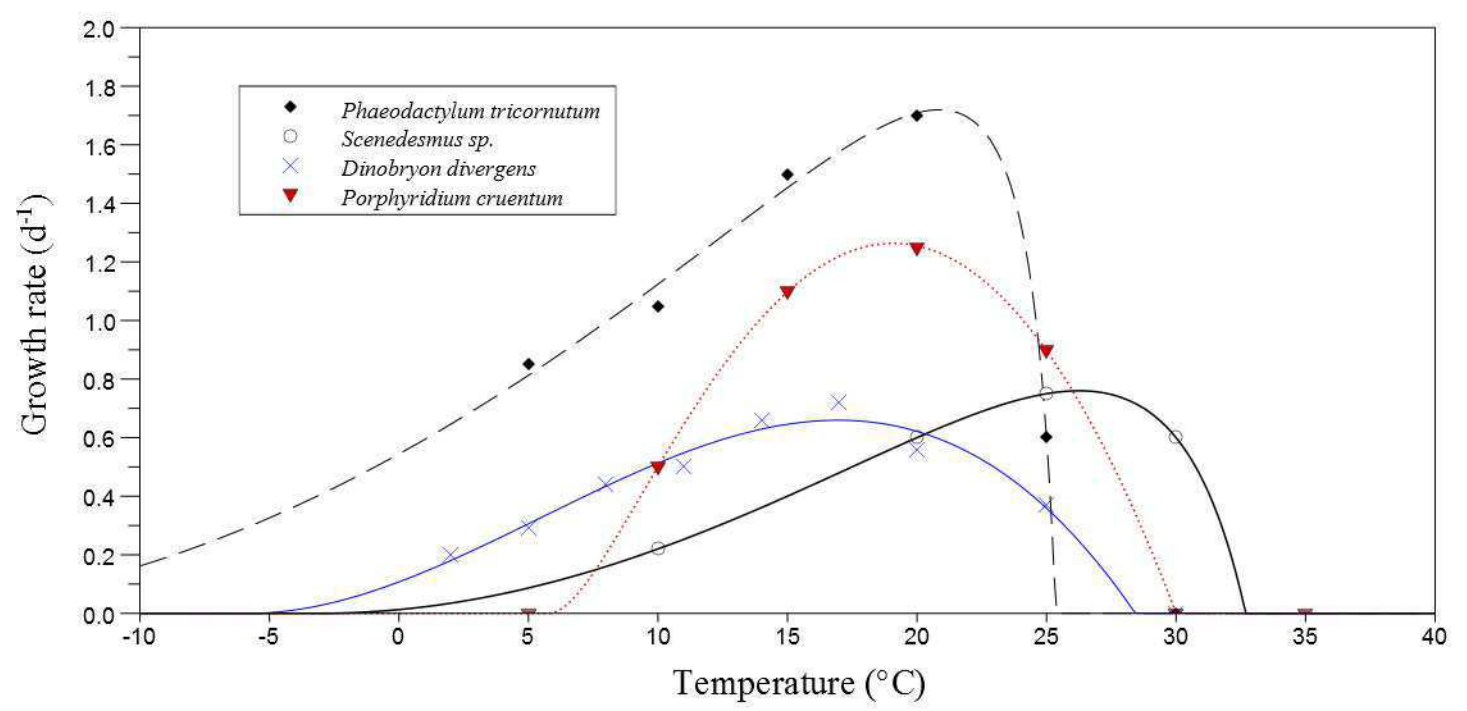

Figure 1. Temperature effect on microalgae growth rates (Butterwick et al., 2005; Kudo et al., 2000; Xin et al., 2011; Dermoun and Chaumont, 1992).

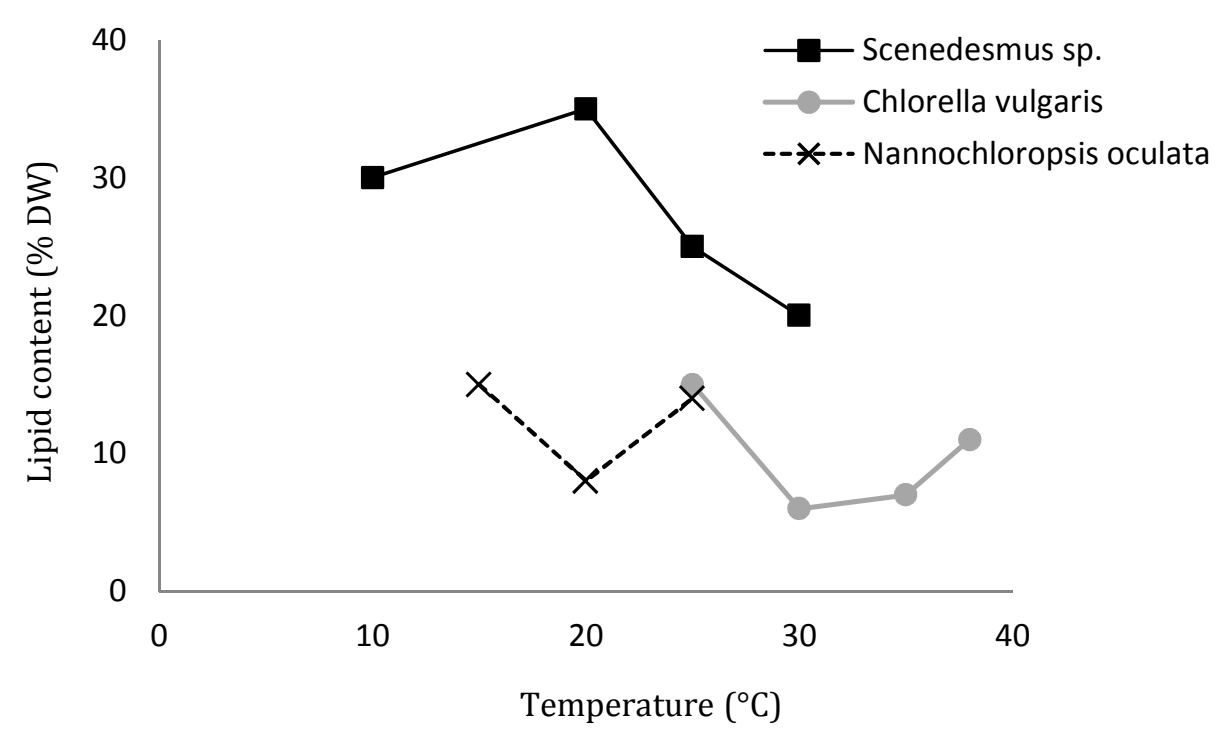

Figure 2. Temperature effect on lipid content in microalgae : Scenedsmus sp. (Xin et al., 2011), Chlorella vulgaris and Nannochloropsis oculata (Converti et al., 2009). 


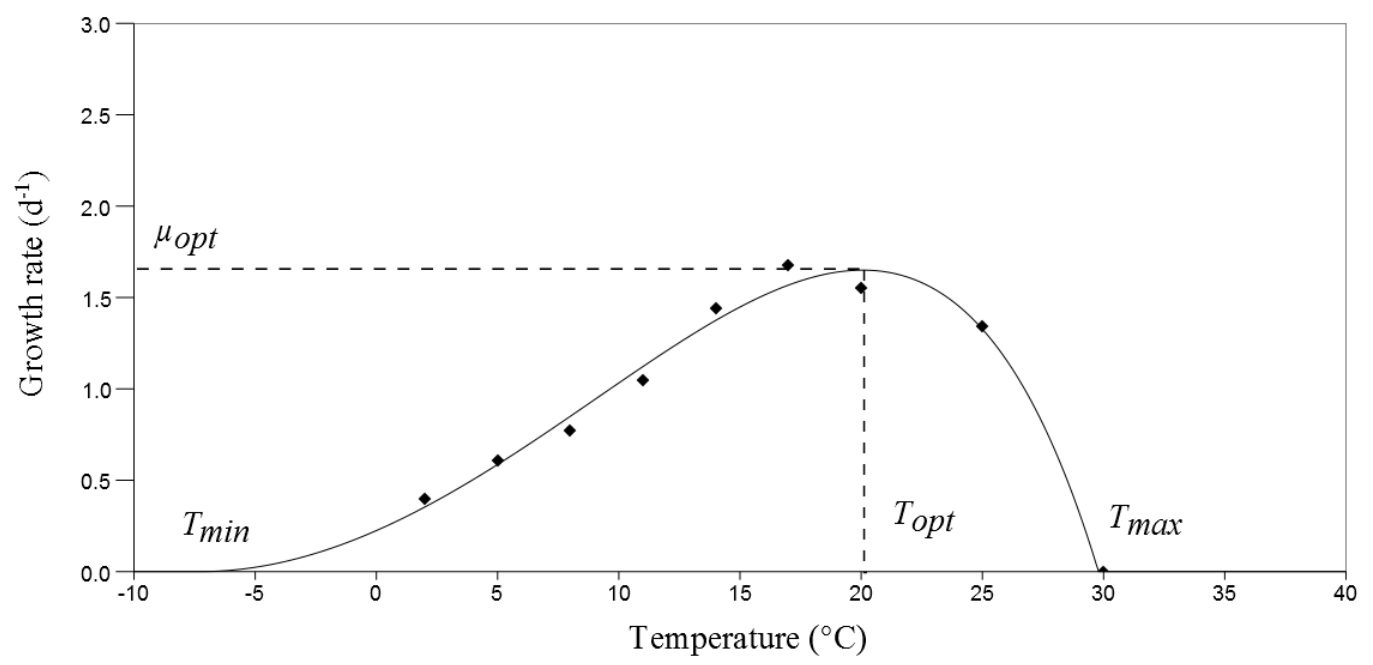

Figure 3. Experimental growth rate for Asterionella formosa (Butterwick et al., 2005) compared to CTMI predictions (curve) as a function of temperature (from Bernard and Rémond, 2012).

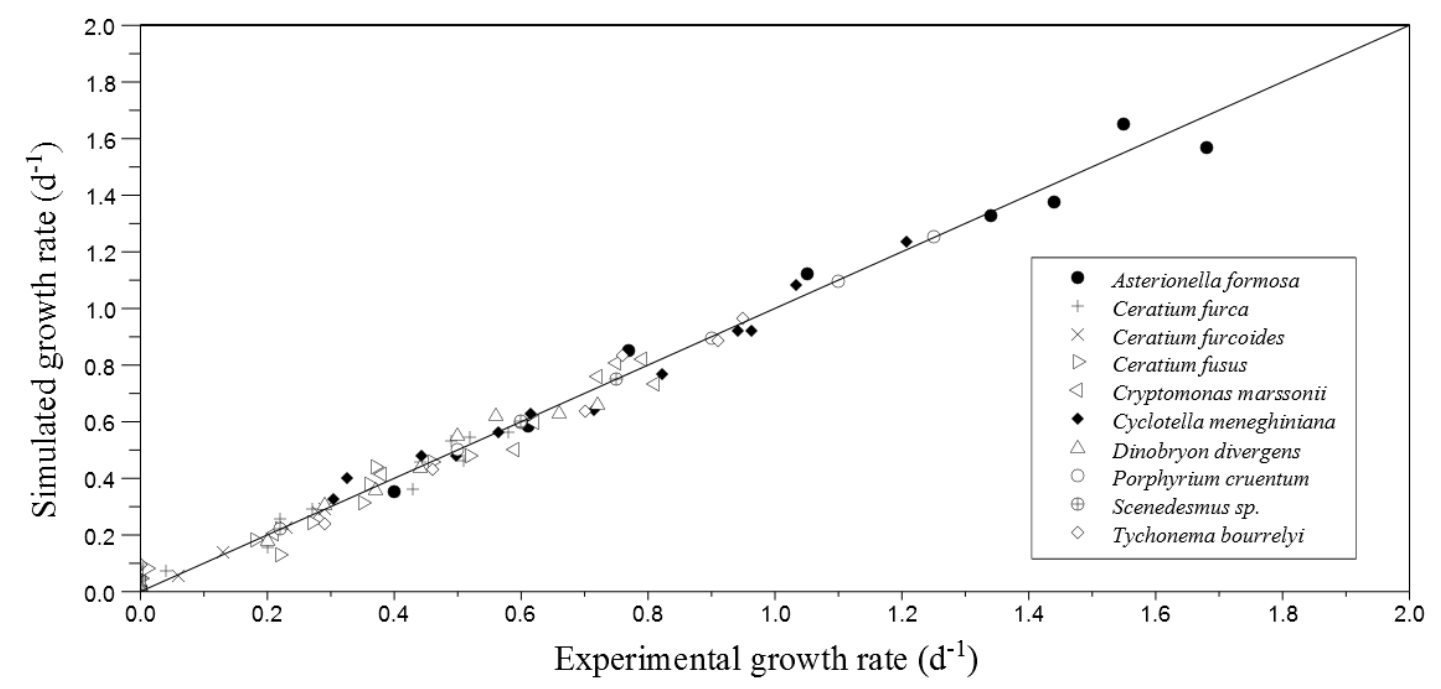

Figure 4. Comparison of growth rate measurements and model predictions for ten species (from Bernard and Rémond, 2012) 


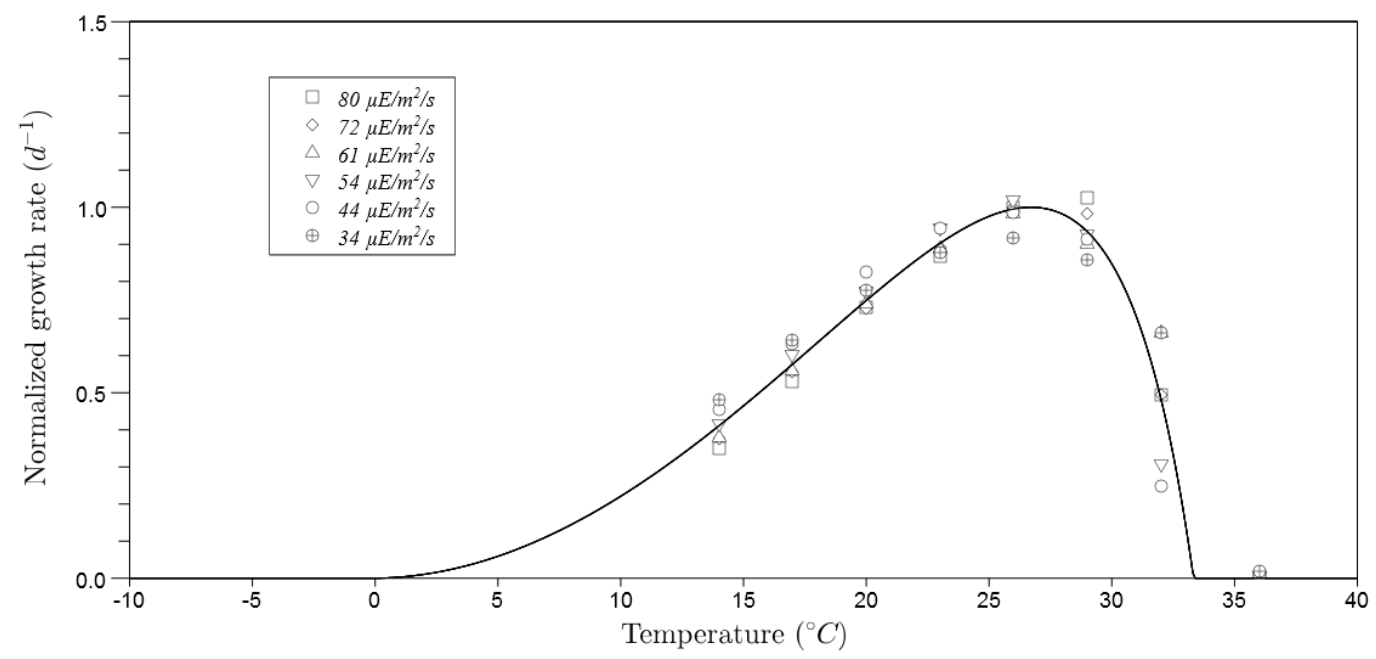

Figure 5. Growth rate of Nannochloropsis oceanica with respect to temperature, at six different light intensities (data from Sandnes et al. (2005)). The growth rate response to temperature has been normalized by its maximal value for each light intensity. 